\title{
Burkholderia oxyphila sp. nov., a bacterium isolated from acidic forest soil that catabolizes $(+)$-catechin and its putative aromatic derivatives
}

\author{
Correspondence \\ Hitoshi Murata \\ murmur@ffpri.affrc.go.jp
}

\author{
Yuichiro Otsuka, ${ }^{1}$ Yuki Muramatsu, ${ }^{2}$ Yasuyoshi Nakagawa, ${ }^{2}$ \\ Motoki Matsuda, ${ }^{3}$ Masaya Nakamura ${ }^{4}$ and Hitoshi Murata ${ }^{4}$ \\ ${ }^{1}$ Department of Biomass Chemistry, Forestry and Forest Products Research Institute, \\ Matsunosato 1, Tsukuba, Ibaraki 305-8687, Japan \\ ${ }^{2}$ Resource Collection Division, NITE Biological Resource Centre Department of Biotechnology, \\ National Institute of Technology and Evaluation, 2-5-8 Kazusakamatari, Kisarazu-shi, \\ Chiba 292-0818, Japan \\ ${ }^{3}$ Toyama Prefectural University, Kurokawa 5180, Imizu, Toyama 939-0398, Japan \\ ${ }^{4}$ Department of Applied Microbiology and Mushroom Sciences, Forestry and Forest Products \\ Research Institute, Matsunosato 1, Tsukuba, Ibaraki 305-8687, Japan
}

A novel bacterium, designated strain $\mathrm{OX}-01^{\top}$, was isolated from acidic soil, taxonomically investigated and identified as an agent that catabolizes $(+)$-catechin into taxifolin. Strain OX-01 ${ }^{\top}$ is a Gram-reaction-negative, aerobic, non-sporulating, non-motile and rod-shaped bacterium. $16 \mathrm{~S}$ rRNA gene sequence analysis identified this strain as a member of the genus Burkholderia and occupying a phylogenetic position closest to, but clearly distinct from, Burkholderia sacchari. Strain $\mathrm{OX}-01^{\top}$ does not have any nif genes, which are required for $\mathrm{N}_{2}$-fixation, in its genome, a feature that is similar to $B$. sacchari, which lacks $n i f H$, but is distinct from the $\mathrm{N}_{2}$-fixing features of many other phylogenetically related taxa, such as Burkholderia ferrariae, B. heleia, B. mimosarum, $B$. nodosa, B. silvatlantica, $B$. tropica and $B$. unamae. Strain $\mathrm{OX}-01^{\top}$ has the following chemotaxonomic characteristics: the major ubiquinone is $Q-8$, the DNA G+C content is 64 mol\% and the major fatty acids are $\mathrm{C}_{16: 0}, \mathrm{C}_{17: 0}$ cyclo and $\mathrm{C}_{18: 1} \omega 7 \mathrm{c}$. It also has a unique profile of carbohydrate utilization among other species of the genus Burkholderia. The strain cannot assimilate many pentoses, hexoses and oligosaccharides, whereas it can catabolize $(+)$-catechin and its putative aromatic derivatives, such as 4-hydroxy-3-methoxycinnamic acid, protocatechuic acid, $p$-hydroxybenzoic acid, trans-p-coumaric acid and vanillic acid. Based on its morphological, physiological and chemotaxonomic characteristics, together with DNA-DNA relatedness values and $16 \mathrm{~S}$ rRNA gene sequence comparison data, we show that strain OX-O1 ${ }^{\top}$ represents a novel species of the genus Burkholderia, for which the name Burkholderia oxyphila sp. nov. is proposed. The type strain is OX-01 ${ }^{\top}\left(=\right.$ NBRC $105797^{\top}=$ DSM $\left.22550^{\top}\right)$.
The genus Burkholderia comprises more than 50 species, many of which exist in association with soils, aquatic zones, fungi, plants and animals (Vandamme et al., 2007) and confer great influence on terrestrial ecosystems and human society. Many of them are decomposers of biomass, biodegraders of toxic chemicals, pathogens of a variety of higher organisms, producers of anti-microbial compounds, endosymbionts and quasi-organelles of fungi, or plant growth promoters (Aizawa et al., 2010; Aspray et al., 2006; Coenye \& Vandamme, 2003; Estrada-de los Santos et al., 2001; Izumi et al., 2006; Lehning et al., 1997; Levy et al.,

The GenBank/EMBL/DDBJ accession number for the 16S rRNA gene sequence of strain $O X-01^{\top}$ is $A B 488693$.
2003; Lim et al., 2003; Martínez-Aguilar et al., 2008; Minerdi et al., 2001; Seigle-Murandi et al., 1996; Vandamme et al., 2007).

We have recently isolated a strain, designated $O X-01^{\mathrm{T}}$, that transforms $(+)$-catechin, a component of tannins, into taxifolin through a two-step oxidation process under the acidic conditions of a forest soil in Japan. This feature could be exploited for the biotransformation of components found in wood not suitable for lumber, especially in bark that contains a large amount of tannin, into raw materials, such as 2-pyrone-4,6-dicarboxylic acid (Otsuka et al., 2006). In the present study, we carried out polyphasic taxonomic analysis on strain $\mathrm{OX}-01^{\mathrm{T}}$ and found that this 
bacterium represents a novel species that is closely related to, but is independent of, Burkholderia sacchari.

Unless stated otherwise, strain $\mathrm{OX}-01^{\mathrm{T}}$ was stored on a Pseudomonas agar $\mathrm{F}$ plate (Difco) at $4{ }^{\circ} \mathrm{C}$ or in $10 \%$ skimmed milk solution at $-80{ }^{\circ} \mathrm{C}$ and was cultured aerobically in either LB broth or in minimal salts medium containing $0.2 \%$ glucose and $55 \mathrm{mM}$ potassium phosphate (pH 6.8) at $28{ }^{\circ} \mathrm{C}$ for $24 \mathrm{~h}$ prior to the experiments (Miller, 1972). To confirm that the culture maintained its $(+)$ catechin-decomposing capacity, colonies were plated onto $\mathrm{W}$-medium containing $0.2 \%(+)$-catechin, $\mathrm{pH} 3.5$ (Yano \& Nishi, 1980). After culture and observation under a phase-contrast microscope, it was established that strain $\mathrm{OX}-01^{\mathrm{T}}$ is a Gram-reaction-negative, non-sporulating, non-motile, rod-shaped bacterium $0.8-0.9 \mu \mathrm{m}$ wide and $1.5-2.0 \mu \mathrm{m}$ long. It grew both aerobically and anaerobically on LB and minimal glucose media and formed smooth, butter-like yellowish-white colonies on the LB plate. The optimal temperature for growth was $30^{\circ} \mathrm{C}$ and the maximum temperature for growth was $40{ }^{\circ} \mathrm{C}$. No growth was noted at temperatures above $42{ }^{\circ} \mathrm{C}$ or below $15{ }^{\circ} \mathrm{C}$. Strain $\mathrm{OX}-01^{\mathrm{T}}$ grew at $\mathrm{pH}$ 3.5-8.0.

The 16S rRNA gene was amplified from genomic DNA of strain OX $-01^{\mathrm{T}}$ by PCR using TaKaRa LA Taq polymerase (Takara) and the $16 \mathrm{~S}$ rRNA gene universal primers $27 \mathrm{f}$ and 1492r (Johnston, 1994). The nucleotide sequence of the 1493 bp fragment was analysed with a BigDye terminator FS core kit version 3.1 and an ABI3100 autosequencer (Applied Biosystems). Primers used for sequencing are as follows: M13-21 and M13-R of the vector PCR2.1 and 5'TGATCCAGCAATGCCGCGT- $3^{\prime}$ and 5' -GCCAATACTGACGCTCATG-3' targeting positions 356-374 and 712-730 of the insert DNA, respectively. The internal $1455 \mathrm{bp}$ sequence was aligned with the corresponding sequences of species of the genus Burkholderia that had the highest sequence similarity to strain OX- $01^{\mathrm{T}}$ in the BLAST search. Sequences obtained were aligned with those of members of the genus Burkholderia by using CLUSTAL_X (Thompson et al., 1997) and then modified manually by referring to the
16S rRNA secondary structure of Escherichia coli (Gutell et al., 1994) and using the BioEdit sequence alignment editor (http://www.mbio.ncsu.edu/BioEdit/bioedit.html). Phylogenetic trees were reconstructed by the neighbourjoining method (Saitou \& Nei, 1987) with calculated $K_{\text {nuc }}$ values (Kimura, 1980). The topology of the tree was evaluated by bootstrap analysis (Felsenstein, 1985) with 1000 replicates. The phylogenetic tree based on the neighbour-joining method was consistent with that based on the maximum-parsimony method when carried out separately and showed that strain $\mathrm{OX}-01^{\mathrm{T}}$ represents a novel species of the genus Burkholderia (Fig. 1).

To explore the biochemical properties of $\mathrm{OX}-01^{\mathrm{T}}$, the strain was precultured in LB medium at $30{ }^{\circ} \mathrm{C}$ for $24 \mathrm{~h}$ and examined using the API 20NE, API $50 \mathrm{CH}$ and API ZME systems by following the manufacturer's instructions (bioMérieux). Differential analysis between strain OX- $01^{\mathrm{T}}$ and phylogenetically related taxa was carried out three times; representative data are shown in Table 1.

Strain $\mathrm{OX}-01^{\mathrm{T}}$ produces catalase but not oxidase. The following tests are positive: acid phosphatase, alkaline phosphatase, C4 esterase, C8 esterase lipase, leucine arylamidase, naphthol-AS-BI-phosphohydrolase, urease and the assimilation of D-arabitol, adipic acid, $\mathrm{N}$-acetylD-glucosamine, $n$-capric acid, fructose, gluconate, glucose, 2-ketogluconate, DL-malate, D-mannitol, D-mannose, phenylacetate, potassium gluconate, sodium citrate, sorbose and sorbitol. The following tests are negative: the production of acid and gas from glucose, oxidation and fermentation of glucose, indole production, nitrate reduction, hydrolysis of gelatin and aesculin, growth on MacConkey agar, $N$-acetyl- $\beta$-glucosaminidase, arginine dihydrolase, chymotrypsin, cystine arylamidase, cytochrome oxidase, C14 lipase, $\alpha$-fucosidase, $\alpha$ - and $\beta$ galactosidase, $\beta$-glucuronidase, $\alpha$ - and $\beta$-glucosidase, $\alpha$ mannosidase, trypsin, valine arylamidase and the assimilation of adonitol, amygdalin, DL-arabinose, L-arabitol, arbutin, cellobiose, dulcitol, erythritol, aesculin, DL-fucose, galactose, gentiobiose, glycerol, glycogen, myo-inositol,

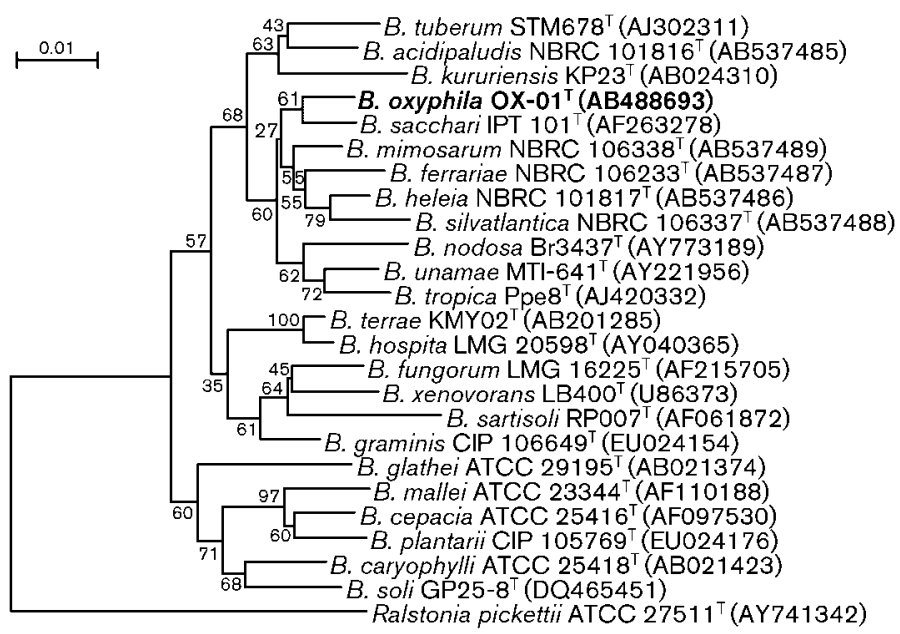

Fig. 1. Phylogenetic tree based on the $16 \mathrm{~S}$ rRNA gene sequences of strain $\mathrm{OX}-01^{\top}$ and related taxa. The tree, based on the nearly complete sequence of the 16S rRNA gene, was created by using the neighbour-joining method. Numbers indicate percentages of bootstrap samplings, derived from 1000 replications. Bar, 0.01 substitutions per nucleotide site. 
Table 1. Differential characteristics of strain $\mathrm{OX}-01^{\top}$ and type strains of phylogenetically related species of the genus Burkholderia

Taxa: 1, strain OX-01 ${ }^{\mathrm{T}}$; 2, B. sacchari DSM $17165^{\mathrm{T}}$ (data from Brämer et al., 2001); 3, B. unamae DSM 17197 ${ }^{\mathrm{T}}$ (Caballero-Mellado et al., 2004); 4 , B. tropica DSM $15359^{\mathrm{T}}$ (Reis et al., 2004); 5, B. ferrariae NBRC 106233 ${ }^{\mathrm{T}}$ (Valverde et al., 2006); 6, B. silvatlantica NBRC 106337 ${ }^{\mathrm{T}}$ (Perin et al., 2006); 7 , B. mimosarum NBRC $106338^{\mathrm{T}}$ (Chen et al., 2006); 8, B. nodosa BCRC $17575^{\mathrm{T}}$ (Chen et al., 2007); 9, B. heleia NBRC 101817 ${ }^{\mathrm{T}}$ (Aizawa et al., 2010). + , Good growth; -, no growth; V, variable; ND, no data available.

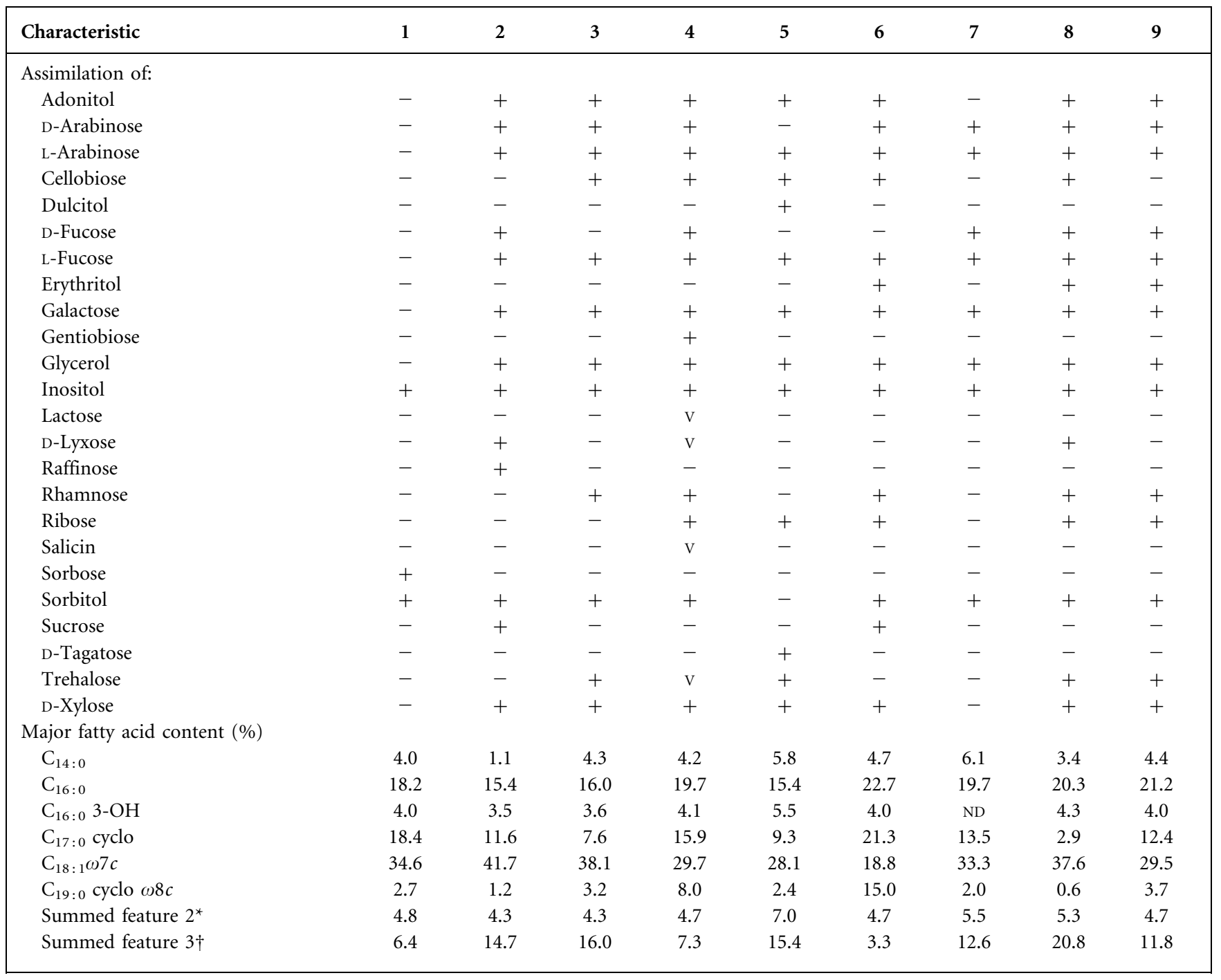

${ }^{*}$ Comprises $\mathrm{C}_{14: 0} 3-\mathrm{OH}$ and/or iso- $\mathrm{C}_{16: 1} \mathrm{I}$.

†Comprises iso- $\mathrm{C}_{15: 0} 2-\mathrm{OH}$ and/or $\mathrm{C}_{16: 1} \omega 7 c$.

inulin, 5-ketogluconate, lactose, D-lyxose, maltose, methyl $\alpha$-D-glucoside, methyl $\alpha$-D-mannoside, melezitose, melibiose, methyl $\beta$-D-xyloside, raffinose, rhamnose, ribose, salicin, starch, sucrose, D-tagatose, trehalose, turanose, xylitol and DL-xylose.

Note that $\mathrm{OX}-01^{\mathrm{T}}$ had a unique profile of carbon source assimilation among species of the genus Burkholderia. OX$01^{\mathrm{T}}$ could not assimilate many pentoses, hexoses or oligosaccharides. On the other hand, this strain could catabolize various aromatic compounds as sole carbon sources, such as $(+)$-catechin, vanillic acid, protocatechuic acid, p-hydroxybenzoic acid, 4-hydroxy-3-methoxybenzoic acid (ferulic acid) and trans-p-coumaric acid.

Cellular fatty acids of all strains were extracted and analysed using the Sherlock Microbial Identification System version 5.0 (MIDI system) and standard MIS Library TSBA40. Briefly, samples of bacteria were cultured on LB agar at $25{ }^{\circ} \mathrm{C}$ for $24 \mathrm{~h}$ and subjected to GC analysis of fatty acid methyl esters by following the protocol recommended by the manufacturer. Differential fatty acid profiles of $\mathrm{OX}-01^{\mathrm{T}}$ and phylogenetically related species of the genus Burkholderia are given in Table 1; the 
profile of strain $\mathrm{OX}-01^{\mathrm{T}}$, including components comprising $>1 \%$ of the total, is as follows: $\mathrm{C}_{14: 0}(4.0 \%), \mathrm{C}_{16: 0}$ (18.2\%), $\mathrm{C}_{16: 0} \quad 2-\mathrm{OH}(2.5 \%), \mathrm{C}_{16: 0} 3-\mathrm{OH} \quad(4.0 \%)$, $\mathrm{C}_{16: 1} 2-\mathrm{OH}(2.0 \%), \mathrm{C}_{17: 0}$ cyclo $(18.4 \%), \mathrm{C}_{18: 1} \omega 7 \mathrm{c}$ (34.6\%), $\mathrm{C}_{19: 0}$ cyclo $\omega 8 c(2.7 \%), \mathrm{C}_{18: 1} 2-\mathrm{OH}(1.6 \%)$, summed feature $2\left(\mathrm{C}_{14: 0} 3-\mathrm{OH} /\right.$ iso- $\left._{16: 1} \mathrm{I} ; 4.8 \%\right)$ and summed feature 3 (iso- $\mathrm{C}_{15: 0} 2-\mathrm{OH} / \mathrm{C}_{16: 1} \omega 7 c ; 6.4 \%$ ). While the fatty acid composition of strain $\mathrm{OX}-01^{\mathrm{T}}$ is similar to that of other species of the genus Burkholderia, the entire profile does not match that of any bacterial species in the database.

The quinone system was analysed by using the standard protocol of Nishijima et al. (1997). Briefly, ubiquinones were extracted with chloroform/methanol (2:1) from dried bacterial cells that had been aerobically cultured in trypticase soy broth at $30{ }^{\circ} \mathrm{C}$ for $48 \mathrm{~h}$. The extracts, dissolved in acetone, were analysed by using the Waters 600 HPLC system equipped with an Inersil ODS-3 $(4.6 \times 150 \mathrm{~mm}$; GL Science $)$ column. The analysis showed that the major ubiquinone in strain $\mathrm{OX}-01^{\mathrm{T}}$ is $\mathrm{Q}-8$.

Total DNA was isolated from strain $\mathrm{OX}-01^{\mathrm{T}}$, B. sacchari DSM $17165^{\mathrm{T}}$ (Brämer et al., 2001), Burkholderia unamae DSM $17197^{\mathrm{T}}$ (Caballero-Mellado et al., 2004), Burkholderia mimosarum NBRC $106338^{\mathrm{T}}$ (Chen et al., 2006), Burkholderia tropica DSM $15359^{\mathrm{T}}$ (Reis et al., 2004), Burkholderia heleia NBRC $101817^{\mathrm{T}}$ (Aizawa et al., 2010), Burkholderia ferrariae NBRC $106233^{\mathrm{T}}$ (Valverde et al., 2006), Burkholderia silvatlantica NBRC $106337^{\mathrm{T}}$ (Perin et al., 2006) and Burkholderia nodosa BCRC $17575^{\mathrm{T}}$ (Chen et al., 2007) by using the standard protocol of Staskawicz et al. (1984) for pseudomonads. Samples were purified by cesium chloride/ ethidium bromide density-gradient ultracentrifugation. To remove ethidium bromide and cesium chloride, the DNA band isolated was dissolved in 2-propanol saturated with $\mathrm{NaCl}$ and dialysed repeatedly against TE buffer. The DNA $\mathrm{G}+\mathrm{C}$ content of strain $\mathrm{OX}-01^{\mathrm{T}}$, based on a standard method described by Takagi et al. (1993), was estimated to be $64 \mathrm{~mol} \%$. The $16 \mathrm{~S}$ rRNA gene sequence similarity between $\mathrm{OX}-01^{\mathrm{T}}$ and $B$. sacchari DSM $17165^{\mathrm{T}}$, B. unamae DSM $17197^{\mathrm{T}}$, B. mimosarum NBRC $106338^{\mathrm{T}}$, B. tropica DSM $15359^{\mathrm{T}}$, B. heleia NBRC $101817^{\mathrm{T}}$, B. ferrariae NBRC $106233^{\mathrm{T}}, B$. silvatlantica NBRC $106337^{\mathrm{T}}$ and $B$. nodosa BCRC $17575^{\mathrm{T}}$ was $98.8,98.0,97.7,97.5,97.5,97.3,97.0$ and $96.8 \%$, respectively.

DNA-DNA reassociation levels between strain $\mathrm{OX}-01^{\mathrm{T}}$ and type strains of phylogenetically related species of the genus Burkholderia were determined by hybridization in the presence of $50 \%$ formamide at $50{ }^{\circ} \mathrm{C}$ followed by quantification of hybridization signals with a streptavidin-biotinylated peroxidase detection system (Ezaki et al., 1989). DNA-DNA relatedness values between strain $\mathrm{OX}-01^{\mathrm{T}}$ and proximal taxa $B$. sacchari DSM $17165^{\mathrm{T}}, B$. unamae DSM $17197^{\mathrm{T}}$, B. mimosarum NBRC $106338^{\mathrm{T}}, B$. tropica DSM $15359^{\mathrm{T}}$, B. heleia NBRC $101817^{\mathrm{T}}$, B. ferrariae NBRC $106233^{\mathrm{T}}$, B. silvatlantica NBRC $106337^{\mathrm{T}}$ and $B$. nodosa BCRC $17575^{\mathrm{T}}$ were $46,25,21,22,13,27,37$ and
$24 \%$, respectively, indicating that strain $\mathrm{OX}-01^{\mathrm{T}}$ does not belong to any known species of Burkholderia.

The whole genome of strain $\mathrm{OX}-01^{\mathrm{T}}$ was sequenced by using the Illumina GAII 50 bp pairwise analysis system and data were assembled and annotated using Illumina Pipeline software version 1.3. Genomic information of Burkholderia phytofirmans PsJ $\mathrm{N}^{\mathrm{T}}$, Burkholderia xenovorans $\mathrm{LB} 400^{\mathrm{T}}$ and Burkholderia multivorans ATCC $17616^{\mathrm{T}}$, the species that showed the closest matches in BLAST searches (Otsuka et al., unpublished), was used as a reference. The total read length was $\sim 510 \mathrm{Mbp}$, which should cover the genome of strain OX- $01^{\mathrm{T}}$ over 50 times if its genome size is equal to the average genome size of other species of the genus Burkholderia, especially that of closely related species (6.5-8.6 Mbp; Martínez-Aguilar et al., 2008). BLAST analysis showed that the genome of strain $\mathrm{OX}-01^{\mathrm{T}}$ does not contain nifH, a gene that is required for $\mathrm{N}_{2}$-fixation. This feature is shared by $B$. sacchari but is distinct from the phylogenetically proximal taxa $B$. ferrariae, $B$. heleia, $B$. mimosarum, $B$. nodosa, $B$. silvatlantica, $B$. tropica and $B$. unamae (Aizawa et al., 2010; Chen et al., 2006, 2007; Martínez-Aguilar et al., 2008). In fact, strain $\mathrm{OX}-01^{\mathrm{T}}$ does not have any nif genes in its genome.

These genomic properties underline the results of the biochemical, physiological and chemotaxonomic tests described above, which, when taken together, suggest that strain $\mathrm{OX}-01^{\mathrm{T}}$ represents a novel species of the genus Burkholderia, for which the name Burkholderia oxyphila sp. nov. is proposed.

\section{Description of Burkholderia oxyphila sp. nov.}

Burkholderia oxyphila (ox.y.phi'la. Gr. adj. oxys sharp, acidic; Gr. fem. adj. phila loving; N.L. fem. adj. oxyphila loving an acidic habitat).

Cells are Gram-reaction-negative, both aerobic and anaerobic, non-sporulating, non-motile and rod-shaped, 0.8$0.9 \mu \mathrm{m}$ wide and $1.5-2.0 \mu \mathrm{m}$ long. Colonies are smooth, butter-like and yellowish-white when grown on LB medium. Growth occurs at $15-40{ }^{\circ} \mathrm{C}$ (optimum $30{ }^{\circ} \mathrm{C}$ ) in $\mathrm{LB}$ broth. The $\mathrm{pH}$ range for sustaining growth is $\mathrm{pH} 3.5-$ 8.0. Catabolizes the following non-humic aromatics: $(+)$ catechin $(\mathrm{pH} 3.5)$, vanillic acid $(\mathrm{pH}$ 6.9), protocatechuic acid (pH 6.9), p-hydroxybenzoic acid (pH 6.9), 4hydroxy-3-methoxycinnamic acid $(\mathrm{pH}$ 6.9) and trans- $p$ coumaric acid ( $\mathrm{pH}$ 6.9). Catalase is produced but oxidase is not. Tests for the following attributes are positive: alkaline phosphatase, esterase, esterase lipase, leucine arylamidase, acid phosphatase, naphthol-AS-BI-phosphohydrolase and urease activities and assimilation of glucose, D-mannose, D-mannitol, $\mathrm{N}$-acetyl-D-glucosamine, potassium gluconate, $n$-capric acid, adipic acid, DL-malate, sodium citrate, phenylacetate, fructose, sorbose, sorbitol, D-arabitol, gluconate and 2-ketogluconate. Tests for the following attributes are negative: production of acid and gas from glucose, oxidation and fermentation of glucose, indole production, arginine dihydrolase, nitrate reduction, 
hydrolysis of gelatin and aesculin, $\beta$-galactosidase, growth on MacConkey agar, cytochrome oxidase and assimilation of DL-arabinose, maltose, glycerol, erythritol, ribose, DLxylose, adonitol, methyl $\beta$-D-xyloside, galactose, rhamnose, dulcitol, myo-inositol, methyl $\alpha$-D-mannoside, methyl $\alpha$-Dglucoside, amygdalin, arbutin, aesculin, salicin, cellobiose, lactose, melibiose, sucrose, trehalose, inulin, melezitose, raffinose, starch, glycogen, xylitol, gentiobiose, turanose, Dlyxose, D-tagatose, DL-fucose, L-arabitol and 5-ketogluconate. The major ubiquinone is Q-8. The major fatty acids are $\mathrm{C}_{16: 0}, \mathrm{C}_{17: 0}$ cyclo and $\mathrm{C}_{18: 1} \omega 7 c$. The DNA $\mathrm{G}+\mathrm{C}$ content is $64 \mathrm{~mol} \%$. No nif genes exist in the genome.

The type strain, OX- $01^{\mathrm{T}} \quad\left(=\mathrm{NBRC} 105797^{\mathrm{T}}=\mathrm{DSM}\right.$ $22550^{\mathrm{T}}$ ), was isolated from acidic forest soil from Japan.

\section{Acknowledgements}

This work was supported by a Grant-in-Aid for Young Scientists (Start-up) from KAKENHI (19880035), a Grant-in-Aid for Young Scientists (B) from KAKENHI (21780169) and by a grant from the Ministry of Agriculture, Forestry and Fisheries of Japan.

\section{References}

Aizawa, T., Ve, N. B., Nakajima, M. \& Sunairi, M. (2010). Burkholderia heleia sp. nov., a nitrogen-fixing bacterium isolated from an aquatic plant, Eleocharis dulcis, that grows in highly acidic swamps in actual acid sulfate soil areas of Vietnam. Int J Syst Evol Microbiol 60, 11521157.

Aspray, T. J., Frey-Klett, P., Jones, J. E., Whipps, J. M., Barbaye, J. \& Bending, G. D. (2006). Mycorrhization helper bacteria: a case of specificity for altering ectomycorrhiza architecture but not ectomycorrhiza formation. Mycorrhiza 16, 533-541.

Brämer, C. O., Vandamme, P., da Silva, L. F., Gomez, J. G. C. \& Steinbuchel, A. (2001). Burkholderia sacchari sp. nov., a polyhydroxyalkanoate-accumulating bacterium isolated from soil of a sugar-cane plantation in Brazil. Int J Syst Evol Microbiol 51, 1709-1713.

Caballero-Mellado, J., Martínez-Aguilar, L., Paredes-Valdez, G. \& Estrada-de los Santos, P. (2004). Burkholderia unamae sp. nov., an $\mathrm{N}_{2}$-fixing rhizospheric and endophytic species. Int J Syst Evol Microbiol 54, 1165-1172.

Chen, W.-M., James, E. K., Coenye, T., Chou, J.-H., Barrios, E., de Faria, S. M., Elliott, G. N., Sheu, S.-Y., Sprent, J. I. \& Vandamme, P. (2006). Burkholderia mimosarum sp. nov., isolated from root nodules of Mimosa spp. from Taiwan and South America. Int J Syst Evol Microbiol 56, 1847-1851.

Chen, W.-M., de Faria, S. M., James, E. K., Elliott, G. N., Lin, K.-Y., Chou, J.-H., Sheu, S.-Y., Cnockaert, M., Sprent, J. I. \& Vandamme, P. (2007). Burkholderia nodosa sp. nov., isolated from root nodules of the woody Brazilian legumes Mimosa bimucronata and Mimosa scabrella. Int J Syst Evol Microbiol 57, 1055-1059.

Coenye, T. \& Vandamme, P. (2003). Diversity and significance of Burkholderia species occupying diverse ecological niches. Environ Microbiol 5, 719-729.

Estrada-de los Santos, P., Bustillos-Cristales, R. \& CaballeroMellado, J. (2001). Burkholderia, a genus rich in plant-associated nitrogen fixers with wide environmental and geographic distribution. Appl Environ Microbiol 67, 2790-2798.

Ezaki, T., Hashimoto, Y. \& Yabuuchi, E. (1989). Fluorometric deoxyribonucleic acid-deoxyribonucleic acid hybridization in microdilution wells as an alternative to membrane filter hybridization in which radioisotopes are used to determine genetic relatedness among bacterial strains. Int J Syst Bacteriol 39, 224-229.

Felsenstein, J. (1985). Confidence limits on phylogenies: an approach using the bootstrap. Evolution 39, 783-791.

Gutell, R. R., Larsen, N. \& Woese, C. R. (1994). Lessons from an evolving rRNA: $16 \mathrm{~S}$ and $23 \mathrm{~S}$ rRNA structures from a comparative perspective. Microbiol Rev 58, 10-26.

Izumi, H., Anderson, I. C., Alexander, I. J., Killham, K. \& Moore, E. R. (2006). Endobacteria in some ectomycorrhiza of Scots pine (Pinus sylvestris). FEMS Microbiol Ecol 56, 34-43.

Johnston, J. L. (1994). Similarity analysis of rRNAs. In Methods for General and Molecular Bacteriology, pp. 683-700. Edited by P. Gerhardt, R. G. E. Murray \& W. A. Wood. Washington, DC: American Society for Microbiology.

Kimura, M. (1980). A simple method for estimating evolutionary rates of base substitutions through comparative studies of nucleotide sequences. J Mol Evol 16, 111-120.

Lehning, A., Fock, U., Wittich, R.-M., Timmis, K. N. \& Pieper, D. H. (1997). Metabolism of chlorotoluenes by Burkholderia sp. strain PS12 and toluene dioxygenase of Pseudomonas putida F1: evidence for monooxygenation by toluene and chlorobenzene dioxygenases. Appl Environ Microbiol 63, 1974-1979.

Levy, A., Chang, B. J., Abbott, L. K., Kuo, J., Harnett, G. \& Inglis, T. J. J. (2003). Invasion of spores of the arbuscular mycorrhizal fungus Gigaspora decipiens by Burkholderia spp. Appl Environ Microbiol 69, 6250-6256.

Lim, Y. W., Baik, K. S., Han, S. K., Kim, S. B. \& Bae, K. S. (2003). Burkholderia sordidicola sp. nov., isolated from the white-rot fungus Phanerochaete sordida. Int J Syst Evol Microbiol 53, 1631-1636.

Martínez-Aguilar, L., Díaz, R., Peña-Cabriales, J. J., Estrada-de los Santos, P., Dunn, M. F. \& Caballero-Mellado, J. (2008). Multichromosomal genome structure and confirmation of diazotrophy in novel plant-associated Burkholderia species. Appl Environ Microbiol 74, 4574-4579.

Miller, J. H. (1972). Experiments in Molecular Genetics. Cold Spring Harbor, NY: Cold Spring Harbor Laboratory.

Minerdi, D., Fani, R., Gallo, R., Boarino, A. \& Bonfante, P. (2001). Nitrogen fixation genes in an endosybiotic Burkholderia strain. Appl Environ Microbiol 67, 725-732.

Nishijima, M., Araki-Sakai, M. \& Sano, H. (1997). Identification of isoprenoid quinones by frit-FAB liquid chromatography-mass spectrometry for the chemotaxonomy of microorganisms. J Microbiol Methods 28, 113-122.

Otsuka, Y., Nakamura, M., Shigehara, K., Sugimura, K., Masai, E., Ohara, S. \& Katayama, Y. (2006). Efficient production of 2-pyrone 4,6-dicarboxylic acid as a novel polymer-based material from protocatechuate by microbial function. Appl Microbiol Biotechnol 71, 608-614.

Perin, L., Martínez-Aguilar, L., Paredes-Valdez, G., Baldani, J. I., Estrada-de los Santos, P., Reis, V. M. \& Caballero-Mellado, J. (2006). Burkholderia silvatlantica sp. nov., a diazotrophic bacterium associated with sugar cane and maize. Int J Syst Evol Microbiol 56, 1931-1937.

Reis, V. M., Estrada-de los Santos, P., Tenorio-Salgado, S., Vogel, J., Stoffels, M., Guyon, S., Mavingui, P., Baldani, V. L. D., Schmid, M. \& other authors (2004). Burkholderia tropica sp. nov., a novel nitrogenfixing, plant-associated bacterium. Int J Syst Evol Microbiol 54, 21552162.

Saitou, N. \& Nei, M. (1987). The neighbor-joining method: a new method for reconstructing phylogenetic trees. Mol Biol Evol 4, 406425. 
Seigle-Murandi, F., Guiraud, P., Croizê, J., Falsen, E. \& Eriksson, K.-E. L. (1996). Bacteria are omnipresent on Phanerochaete chrysosporium Burdsall. Appl Environ Microbiol 62, 2477-2481.

Staskawicz, B. J., Dahlbeck, D. \& Keen, N. T. (1984). Cloned avirulence gene of Pseudomonas syringae pv. glycinea determines racespecific incompatibility on Glycine max (L.) Merr. Proc Natl Acad Sci U S A 81, 6024-6028.

Takagi, H., Shida, O., Kadowaki, K., Komagata, K. \& Udaka, S. (1993). Characterization of Bacillus brevis with descriptions of Bacillus migulanus sp. nov., Bacillus choshinensis sp. nov., Bacillus parabrevis sp. nov., and Bacillus galactophilus sp. nov. Int J Syst Bacteriol 43, 221-231.

Thompson, J. D., Gibson, T. J., Plewniak, F., Jeanmougin, F. \& Higgins, D. G. (1997). The CLUSTAL_X windows interface: flexible strategies for multiple sequence alignment aided by quality analysis tools. Nucleic Acids Res 25, 4876-4882.

Valverde, A., Delvasto, P., Peix, A., Velázquez, E., Santa-Regina, I., Ballester, A., Rodríguez-Barrueco, C., García-Balboa, C. \& Igual, J. M. (2006). Burkholderia ferrariae sp. nov., isolated from an iron ore in Brazil. Int J Syst Evol Microbiol 56, 2421-2425.

Vandamme, P., Govan, J. R. W. \& LiPuma, J. J. (2007). Diversity and role of Burkholderia spp. In Burkholderia: Molecular Microbiology and Genomics, pp. 1-28. Edited by T. Coenye \& P. Vandamme. Wymondham, UK: Horizon Bioscience.

Yano, K. \& Nishi, T. (1980). pKJ, a naturally occurring conjugative plasmid coding for toluene degradation and resistance to streptomycin and sulfonamides. J Bacteriol 143, 552-560. 